\title{
La música infantil para desarrollar el aprendizaje significativo en el área Ciencias Naturales
}

\section{Children's music to develop meaningful learning in the area of Natural Sciences}

Sofía Alexandra Cunalata Ramón. ${ }^{1}$ \& Víctor Daniel Aldás Rovayo. ${ }^{2}$

\section{Abstract. \\ DOI: https://doi.org/10.33262/cienciadigital.v3i2.6.520}

The quality of learning that a student acquires depends to a large extent on the resources and methodologies that the teacher uses within the pedagogical practice. Therefore, this research document aims to analyze the use of music to develop meaningful learning in the area of Natural Sciences, to Third Year students of E.G.B. of the Educational Unit "Hispano América", province of Tungurahua, Ecuador. An exploratory and descriptive study was carried out, where the totality of the population was worked on having been less than 100 people, the same one that consisted of 2 teachers and 66 students. The results obtained from the surveys were interpreted and analyzed through the representation of tables and graphs. Those reflect the scarce use of music as a resource, by teachers, for the development of meaningful learning. One of the causes is the ignorance about the benefits offered by this artistic medium within the pedagogical process.

Keywords: Children's Music, Meaningful Learning, Motivation, Understanding, Assimilation of Knowledge.

\section{Resumen.}

La calidad de aprendizaje que adquiera un estudiante, depende en gran medida de los recursos y metodologías que utilice el docente dentro de la práctica pedagógica. Por lo tanto, el presente documento de investigación tiene como objetivo analizar la utilización de la música para desarrollar el aprendizaje significativo en el área de

\footnotetext{
${ }^{1}$ Universidad Técnica de Ambato, Ambato, Ecuador, scunalata4222@uta.edu.ec
}

${ }^{2}$ Universidad Técnica de Ambato, Ambato, Ecuador, vd.aldasr@uta.edu.ec 
Ciencias Naturales, a los estudiantes de Tercer Año de E.G.B. de la Unidad Educativa "Hispano América", provincia de Tungurahua, Ecuador. Se realizó un estudio exploratorio y descriptivo, donde se trabajó con la totalidad de la población por haber sido menor a 100 personas, la misma que estuvo conformada por 2 docentes y 66 estudiantes. Los resultados obtenidos de las encuestas se interpretaron y analizaron por medio de la representación de tablas y gráficos. Aquellos plasman la escasa utilización de la música como un recurso, por parte de los docentes, para el desarrollo del aprendizaje significativo. Una de las causas es el desconocimiento sobre los beneficios que ofrece este medio artístico dentro del proceso pedagógico.

Palabras claves: Música Infantil, Aprendizaje Significativo, Motivación, Comprensión, Asimilación del Conocimiento.

\section{Introducción.}

Desde épocas antiguas hasta la actualidad, la música ha estado inmersa en nuestra vida cotidiana. Los ritmos, armonías y melodías en conjunto permiten al ser humano expresar sentimientos y emociones, es el uso que generalmente se dan a las canciones. Sin embargo, la música brinda otros beneficios, más aún en el contexto educativo.

Si bien es cierto, los profesionales de la educación, suelen utilizar recursos didácticos de apoyo para afianzar el conocimiento en sus alumnos. La mayoría de ellos están enmarcados en los más comunes como: la pizarra y el libro, en ciertas ocasiones carteles o materiales tecnológicos, los cuales no siempre están al alcance. Sin embargo, existen otras herramientas lúdicas que permiten que los dicentes se motiven por aprender, participen activamente y por ende adquieran el conocimiento esperado. Es por ello, que, dentro del ámbito educativo, se puede utilizar la música como un material didáctico que ayude a los estudiantes a desarrollar habilidades cognitivas como: la concentración, la atención, la memoria y la comprensión; como medio de motivación y también para desarrollar aspectos actitudinales y sociales.

El currículo de la Educación General Básica (E.G.B.) del Ecuador integra el área de Educación Cultural y Artística, que involucra a la música como una de las asignaturas complementarias para el desarrollo integral de los estudiantes en las demás áreas, pero con más énfasis en la Educación General Básica en el subnivel de preparatoria, que trata a niños de primer año ( 5 años de edad), debido a que en esta etapa a los niños les divierte mucho interactuar con este recurso. Además, vivimos en un mundo globalizado en donde las nuevas necesidades sociales obligan a la formación de los estudiantes en otras asignaturas afines a aquellas, por ello la importancia de implementar una asignatura artística dentro del currículo educacional ecuatoriano.

Otro objetivo al implementarla es que el alumno desarrolle al máximo una serie de procesos mentales como: el análisis, la identificación, la asociación, la creatividad, la creación, el 
razonamiento, la deducción e inducción, etc. Dichos aspectos justifican el perfil de un estudiante apto para resolver problemas de la vida cotidiana.

Además, esta asignatura artística se interrelaciona con las materias básicas: Lengua y Literatura, Matemática, Ciencias Naturales y Ciencias Sociales como eje transversal, por lo tanto, se la considera un elemento importante del currículo que complementa la adquisición del aprendizaje en los estudiantes (Currículo del área de Educación Cultural y Artística (E.C.A.), 2016).

La música como recurso didáctico en el Ecuador es muy poco utilizada por parte de los docentes para ayudar a que los estudiantes desarrollen un aprendizaje significativo. Esta herramienta está inmersa en la materia de Educación Cultural y Artística del currículo ecuatoriano, sin embargo, no es tomada en cuenta como un medio para innovar la práctica didáctica dentro del aula. Otro punto para analizar, es la cultura ecuatoriana carente de la apreciación del arte musical, esto hace que desconozcamos los múltiples beneficios que tiene la música, sobre todo en la educación.

Actualmente, el sistema educativo está basado en una pedagogía crítica-constructiva, la cual, según el enfoque piagetiano, se trata de poner al alumno en primera instancia y hacerle partícipe de la construcción de su propio conocimiento, ser crítico y analítico, desarrollar la lógica y la creatividad, mientras que el maestro se convierte en un facilitador y guía del proceso, siempre y cuando exista una adecuada comunicación oral de por medio. Para complementar la teoría del constructivismo, Vygotsky realiza un aporte importante enfocado en que el proceso de aprendizaje se logra primero a través de la interacción con los demás y después se la interioriza cognitivamente. Es decir, surge un aprendizaje cooperativo como estrategia (Tünnermann, El constructivismo y el aprendizaje de los estudiantes, 2011).

Para hacer efectivo el proceso de enseñanza-aprendizaje, el docente debe manejar estrategias metodológicas adaptadas al contexto áulico, acompañadas de la utilización de recursos didácticos que ayuden a fortalecer la adquisición de los contenidos curriculares del área de Ciencias Naturales. Es por eso, que Estrada (2016) considera a la música infantil como una herramienta lúdica que facilita la comprensión de la información, debido a que integra melodías, armonías, ritmo y un contenido que llama la atención al niño, lo divierte y lógicamente aprende.

La asignatura de Ciencias Naturales está dentro del currículo ecuatoriano y se imparte en los establecimientos educativos, desde segundo a décimo año de E.G.B. Está enfocada en el conocimiento y en la investigación científica sobre los seres vivos y su interacción con el entorno, el ser humano y la salud, materia y energía, ciencia en acción, el universo y la tierra, dichos temas de estudio ayudarán al estudiante a acercarse y a preservar el medio natural que le rodea, partiendo de la aceptación y el cuidado de sí mismo. Además, esta materia se basa 
principalmente en un sinnúmero de teorías científicas de todos los seres vivos, las mismas que deben ser estudiadas respetando los conceptos y leyes ya establecidos.

Por consiguiente, para que el estudio de todos estos aspectos sea fácil de comprender, se puede aplicar la música como un medio de apoyo para desarrollar el aprendizaje significativo. El docente está en la capacidad de crear sus propias canciones sobre determinado tema de Ciencias Naturales, siempre y cuando sean llamativas para el niño. Además, deben estar adecuadas al año de educación básica, con un vocabulario entendible, utilizando medios tecnológicos auxiliares como: una grabadora, una computadora o proyector; canciones acompañadas de movimientos corporales o faciales que ayuden a que el conocimiento perdure en su estructura cognitiva y sea comprendido (García, 2010).

\section{Recursos didácticos de enseñanza-aprendizaje}

\section{Definición:}

La mayoría de autores asumen como sinónimos las palabras recurso, medio y material didáctico ya que son las más utilizadas para referirse a aquello. Sin embargo, no llegan a un acuerdo sobre su significado (Moreno, 2004).

Es por ello que Zabala (citado por Moreno, 2004) define a los materiales curriculares como: "Instrumentos y medios que proveen al educador de pautas y criterios para la toma de decisiones, tanto en la planificación como en la intervención directa en el proceso de enseñanza". (p. 2)

Por otro lado, la revista digital para profesionales de la enseñanza (2009) en uno de sus párrafos define como recurso didáctico:

"Cualquier recurso que el profesor prevea emplear en el diseño o desarrollo del currículum para aproximar o facilitar los contenidos, mediar en las experiencias de aprendizaje o provocar encuentros o situaciones para facilitar o enriquecer la evaluación”. (p. 1)

Además A. San Martín (citado por Moreno, 2004) afirma que los materiales didácticos son: "Aquellos artefactos que, en unos casos utilizando las diferentes formas de representación simbólica y en otros como referentes directos (objeto), incorporados en estrategias de enseñanza, coadyuvan a la reconstrucción del conocimiento aportando significaciones parciales de los conceptos curriculares”. (p. 2-3)

Los autores citados anteriormente definen a los recursos didácticos como los materiales tangibles que el maestro utiliza tanto en el proceso de enseñanza-aprendizaje como en la evaluación. Por ejemplo: hojas, libros, cuadernos, pizarra, borrador, marcadores, internet, grabadora, proyector, computadora, papelotes, colores, etc., para facilitar a los estudiantes la comprensión y la adquisición de los contenidos curriculares 


\section{Tipos de recursos didácticos}

La revista digital para profesionales de la enseñanza (2009), clasifica a los recursos didácticos según la facilidad para que el docente elija el recurso adecuado.

Recursos experienciales directos: son materiales concretos que se involucran en cualquier momento del proceso de enseñanza-aprendizaje dentro o fuera del aula y permiten al alumno tener una experiencia directa con la realidad. Por ejemplo: una planta, un museo, salida de campamento, siempre y cuando el docente considere que son útiles para la motivación, comprensión y retención de información sobre un determinado tema de estudio.

Recursos estructurales o propios del ámbito escolar: son los que se encuentran en la institución educativa y sirven principalmente para complementar el proceso educacional dentro de las aulas. Por ejemplo: laboratorios, bibliotecas, canchas, gimnasio, etc.

Recursos simbólicos: son representaciones en escalas no reales (símbolos o imágenes), pero que ayudan al alumno a aproximarse a la realidad. Estos se subdividen en materiales fijos de no proyección como: maquetas, globo terráqueo, maniquíes, etc. Material impreso: libros, cuadernos, hojas, afiches, mapas, etc. Y material presentado a través de medios tecnológicos como: recursos de audio, visuales y audiovisuales.

La imagen: una institución educativa no puede prescindir de las imágenes como recurso didáctico, ya que en la vida cotidiana del estudiante están inmersas siempre. Uno de los recursos didácticos que las plasma son los libros, pero es importante innovar los medios, no trabajar con lo mismo de siempre.

Entre los materiales más comunes que ayudan a presentar imágenes al espectador están: la pizarra, los carteles y los mapas; tienes muchas ventajas como: accesibilidad, tiempo de uso indefinido y versatilidad de uso. Asimismo, el proyector, es otro medio que ayuda a proyectar elementos visuales y de audio, de manera clara y de acuerdo al ingenio del docente.

El sonido: los recursos icónicos (sistema de representación tanto lingüístico como visual, a través de las imágenes) suelen captar mejor la atención si se los acompaña con el sonido. Son muy útiles para el estudio de materias como inglés, música, etc. También se lo puede utilizar como recurso de enseñanza de las asignaturas básicas. Entre ellos encontramos: CDs, tocadiscos, cassette, etc.

Por otra parte, se encuentran las nuevas tecnologías de la enseñanza, que obligan a los maestros a saber cómo utilizarlas ya que en pleno siglo XXI nos gobiernan por completo.

\section{Criterios de selección y uso}

A partir del punto de vista de su utilización didáctica los recursos deben ser seleccionados de acuerdo a su funcionalidad, es decir deben servir como material de apoyo para el docente y 
para el estudiante, siempre y cuando no sustituya el objetivo de enseñar del profesorado ni el de aprender del alumnado. Además, el docente deberá hacer un análisis del contexto estudiantil con el que trabaja (estilos de aprendizaje y dificultades de aprendizaje) para aplicar el recurso apropiado (Moreno, 2004).

\section{La música infantil}

\section{Definición}

Según Estrada (2016) define a la música infantil como uno de los ritmos más trascendentales y utilizados durante la historia hasta la actualidad, como un instrumento que ayuda al aprendizaje de los niños. Ellos la disfrutan aún más cuando se la emplea en juegos, bailes, canciones de cuna, etc.

La música infantil no solo posee un fin lúdico sino también didáctico, ya que permite que los alumnos asimilen el conocimiento, fomenten valores y desarrollen habilidades musicales.

\section{Importancia de la música}

Como bien lo sustenta Gardner (citado por Estrada, 2016) en su teoría de las inteligencias múltiples, la música contribuye al desarrollo de la capacidad memorística y la concentración, a la perfección motora, diferenciación de sonidos y exploración del propio cuerpo. Asimismo, desarrolla el léxico, la expresión de sentimientos y emociones, facilita la asimilación de información, fomenta la creatividad y las relaciones interpersonales.

Lago (2012), persuade a que valoremos la importancia que tiene este arte para los seres humanos:

Para nosotros es más que una definición, mucho más que una materia para ser estudiada, mucho más que un medio de expresión y comunicación. Realmente consideramos que la música lo es todo. Desde un punto de vista educativo, la música estimula todas las facultades del ser humano: abstracción, razonamiento lógico y matemático, imaginación, memoria, orden, compromiso personal mediante la creatividad, etc. (p. 21)

Este sentido total e integral con los que la música cuenta, son elementos fundamentales para el desarrollo del hombre, y el medio perfecto de abrirnos al conocimiento y la ciencia, ya que a través de la música se ponen en funcionamiento todos los medios expresivos con los que cuenta. Le capacita para sentir, conocer, valorar, interpretar y apreciar el hecho sonoro, sus raíces populares, la historia que ha configurado todos los cambios y estilos aparecidos a lo largo de ella, etc. Además, los fenómenos físicos y acústicos que la generan, y todo un sinfín de variables, que hacen de la música algo imprescindible para crecer social y culturalmente más completo. (p. 21)

Además, esta autora añade otro beneficio que tiene la música desde el ámbito de la salud; así lo comprobó con un paciente que padecía Alzheimer, el cual podía gozar por un momento de 
todos recuerdos de su vida, se comunicaba con su esposa solo cuando bailaba con ella. Únicamente en este preciso e importante instante, él lograba hablarle (Lago, 2012).

\section{La música infantil como herramienta educativa}

La música ha estado presente en todo momento de nuestra vida, desde que nacemos hasta la actualidad, absolutamente en todo el entorno en el que nos desenvolvemos están inmersos sonidos, ritmos, melodías, armonías.

Según Palacios (citado por Vides, 2014) piensa que la música desde el punto de vista educativo, estimula todas las facultades del ser humano: comprensión, razonamiento, relajación, imaginación, memoria, creatividad, compromiso personal, motivación, etc.

Además, Piaget (citado por Estrada, 2016) menciona que es de gran ayuda que los docentes utilicen recursos didácticos que ayuden a afianzar conocimientos a los estudiantes.

Por otro lado, Carril (citado por Estrada, 2016) añade que la música es la representación de la cultura de la gente, porque permite expresar la historia y vivencias que los identifica, lo que hace a este arte parte importante de la sociedad contemporánea.

La música tiene beneficios versátiles en el ámbito educativo. Es un medio que le permite desarrollarse al ser humano en todos los aspectos: emocionales, intelectuales, culturales, motivacionales, artísticos y humanos. Es por ello que se la involucra dentro del proceso de enseñanza-aprendizaje porque es una herramienta enriquece plenamente al estudiante.

\section{Usos de la música infantil dentro del proceso de enseñanza-aprendizaje}

A lo largo del proceso didáctico, el maestro puede utilizar la música para lograr diferentes fines:

Ambiental: permite que la música produzca un efecto de tranquilidad, relajación y concentración en los alumnos al realizar tareas académicas, especialmente cuando sean de tipo individuales y requieran un ambiente con estas características. Géneros musicales como el Jazz y el Blues son propicios para estos casos. Además, podemos utilizar música para ambientar sonoramente una dramatización, una lectura en voz alta o una obra de teatro, así darle mayor peso escénico (Bernabeu \& Goldstein, 2009).

Informativo: existen canciones que al escucharlas transmiten información al oyente. Por ejemplo: al escuchar poemas, narraciones o cuentos musicalizados, cuyo contenido transmite el mensaje principal o cualquier otro aspecto que pretendamos adquirir (Bernabeu \& Goldstein, 2009).

Expresivo: es útil para producir un ambiente sonoro adecuado para desarrollar las tareas que nos propongamos. Si ponemos una canción apropiada podremos hacer ver a nuestros alumnos que queremos una clase con una actitud humorística, interactiva, romántica, pasiva, etc. (Bernabeu \& Goldstein, 2009). 
Reflexiva: ciertos géneros de música ayudan a los estudiantes a la introspección, es decir al análisis y meditación personal interno, a desprender del cuerpo emociones negativas, a conocernos mejor, elevar la autoestima, nos hace más sensibles a los estímulos de nuestro alrededor, permite expresarnos con mayor facilidad. En pocas palabras, ayuda a desarrollar nuestra inteligencia intrapersonal como la llamaría Gardner (Bernabeu \& Goldstein, 2009).

Movimiento: cuando empezamos el calentamiento previo a realizar actividades físicas, es necesario poner música acorde a los movimientos, sean estos lentos o rápidos (Bernabeu \& Goldstein, 2009).

Además, al utilizar una canción que favorezca a los estudiantes a retener el contenido, se puede también acompañarla con movimientos corporales o faciales para afianzar el conocimiento.

Imaginación: al momento de la relajación con música, los alumnos pueden dar rienda suelta a su imaginación, pueden adentrarse en ese mundo de fantasía, a crear imágenes mentales distintas a las de la realidad, por lo tanto, ayuda a la distracción por un lapso determinado de tiempo y desarrolla la creatividad (Bernabeu \& Goldstein, 2009).

Captar información: al relacionar una determinada secuencia musical con un mensaje verbal hace que el receptor del mensaje no solo active su sección racional de comprensión lógica del texto sino también ponga en juego sus emociones. Esto le permite asimilar y entender la información, no solo memorizarla ya que trabaja emocional y lógicamente (Bernabeu \& Goldstein, 2009).

Evocación y anticipación: al aplicar una canción previa a empezar la clase, permite al estudiante tener una leve idea del tema que se tratará y a enfocarse directamente en su desarrollo y asimilación (Bernabeu \& Goldstein, 2009).

Encadenamiento y transición: al permitirnos la música a crear imágenes sonoras, situaciones y climas relajados y emotivos, puede servir para marcar la transición de momentos de la secuencia de la clase. Por ejemplo: al iniciarla (relajación), al finalizarla (refuerzo) o también en momentos en donde hay una interrupción y no se la concreta completamente (Bernabeu \& Goldstein, 2009).

\section{La música en el área de Ciencias Naturales}

Una de las asignaturas en la que es de mucha ayuda utilizar la música como recurso didáctico para desarrollar un aprendizaje significativo en los estudiantes, es en Ciencias Naturales. Para esto, el docente está en la capacidad de crear sus propias canciones; tendrá que poner a prueba su creatividad, de modo que combine melodías y armonías junto con letras que llamen la atención al niño, obviamente de acuerdo al año de E.G.B. y al tema de clase. García (2010) menciona que cuando el docente trabaje con niños pequeños (nivel preparatorio), las 
canciones deberán mencionar: los números, las letras, los colores, etc. y en años superiores, que es el caso de los docentes de educación básica (segundo a décimo año) para quienes está dirigido este proyecto de investigación, aplicaremos canciones de acuerdo al tema de clase que estemos tratando. Aquí tenemos un ejemplo de una canción que enseña "El ciclo del agua".

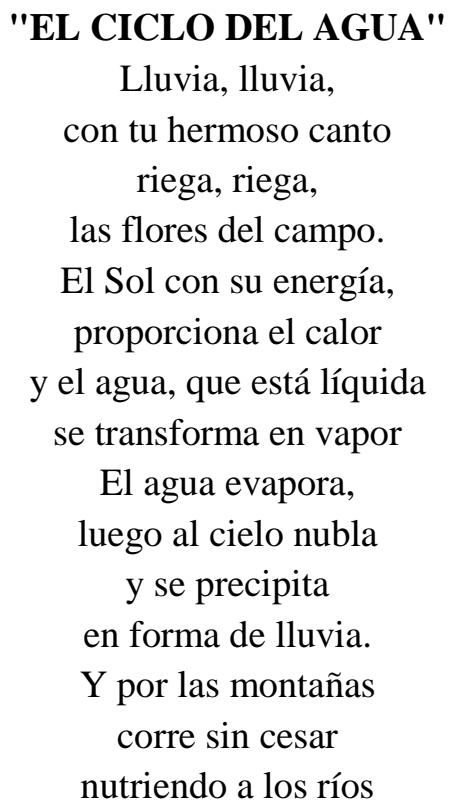

que van hacia el mar. (García, 2010, p. 156)

Como ya hemos mencionado anteriormente, el uso de esta herramienta artística, genera en los estudiantes motivación por querer aprender, por consiguiente, asimilan de manera fácil la información brindada por el docente. Otro punto importante que recalcar es que se la puede aplicar con alumnos de todas las edades, ya que no perderá su efectividad.

\section{Aprendizaje significativo en el área de C.C.N.N.}

\section{Definición de aprendizaje significativo}

Según la perspectiva ausubeliana, Pozo (citado por Rodríguez, 2008) menciona que el aprendizaje significativo estudia el proceso mediante el cual el alumno aprende. Aquí los conocimientos previos que posee el individuo producto de su interacción con el entorno inmediato se relacionan con los nuevos, luego el estudiante los reestructura cognitivamente y finalmente lo construye. Además, el Departamento de Ediciones Educativas de Santillana (2009) basándose también en el enfoque de Ausubel, añade que el alumno a través de dicho proceso está en la capacidad de razonar, comprender y de alguna manera retener el contenido el mayor tiempo posible en su estructura cognitiva. 
Para Novak (citado por Rodríguez, 2011) "El aprendizaje significativo subyace a la integración constructiva de pensamiento, sentimiento y acción, lo que conduce al engrandecimiento humano". (p. 34)

Según este autor, el aprendizaje significativo está dentro de la teoría constructivista. Además, considera importante la parte interna del individuo (sentimientos, emociones) para desarrollar este tipo de aprendizaje.

Por otro lado, Gowin (citado por Rodríguez, 2011) opina que "la enseñanza se consuma cuando el significado del material que el alumno capta es el significado que el profesor pretende que ese material tenga para el alumno". (p. 34)

Para cada tema de clase, el maestro debe plantearse objetivos que sean alcanzables y medibles, es decir debe analizar qué es lo que el alumno debe aprender. Luego deberá utilizar los medios necesarios para llegar con el conocimiento al estudiante, así el proceso tendrá significatividad.

\section{Tipos de aprendizaje significativo}

Según Ausubel (citado por el Departamento de Ediciones Educativas de Santillana, 2009) menciona tres tipos de aprendizaje significativo:

Representacional: se trata de la asimilación de símbolos (conceptos-palabras, números, señales de tránsito, música, mapas, etc.) y su respectiva definición, es decir lo que los nuevos términos representan para el alumno.

\section{¿Cómo funciona el aprendizaje por representaciones?}

Para un niño en su desarrollo inicial del vocabulario, cada palabra tiene un significado real, concreto y especifico. Por ejemplo: la palabra teta, para un niño que está empezando a hablar significa el biberón en el que toma su leche, solo el suyo, no otros diferentes. Pero después de da cuenta que la gente llama teta a todos los biberones que existen, es decir desarrolla un proceso de generalización.

Conceptual: este tipo de aprendizaje está enfocado en el conocimiento y comprensión de todo lo que significa un determinado concepto previo, es decir: su definición, su clasificación, sus características, etc. Una vez que se cumpla este prerrequisito, se podrá relacionarlo con el nuevo conocimiento. Asimismo, este deberá ser ampliado en gran parte para analizarlo, reestructurarlo, comprenderlo y generar conocimientos más elaborados.

Proposicional: se tratan de ideas expresadas mediante frases, parecidas a las leyes (un tanto complejas). Sin embargo, para adquirir este tipo de aprendizaje, no basta solo con saber el significado de cada término que forma aquella oración, sino que es necesario primero comprender otras proposiciones básicas que se relacionan con aquella compleja. Caso 
contrario, el estudiante está destinado a memorizarla, lo que significa que no hay aprendizaje significativo.

\section{Condiciones para lograr un aprendizaje significativo}

a. De carácter personal del aprendiz

\section{Actitud de aprendizaje}

El estudiante debe estar predispuesto a aprender. A participar activamente en el análisis y la comprensión de aquella nueva información, tomando como base la que ya conoce. Otra característica actitudinal es el querer compartir sus saberes y puntos de vista de un tema en específico con el docente y también entre sus pares. (Rodríguez, 2008)

\section{Estructura cognoscitiva apta para aprender}

Es necesario que el alumno tenga prerrequisitos sobre un tema determinado, para relacionarlos con el nuevo conocimiento y comprenderlo. Esta nueva información debe ser lo suficientemente clara, de manera que se puedan notar y establecer diferencias entre lo previo y lo actual. (Departamento de Ediciones Educativas de Santillana, 2009)

b. Características del docente

\section{Capacidad de presentar el conocimiento}

El maestro debe saber de qué manera impartir el conocimiento a profundidad, pertinentemente, de modo persuasivo y claro. Si lo presenta extendiéndolo y aplicando ejemplos relacionados con el tema de estudio, el alumno podrá establecer relaciones y lo comprenderá fácilmente. Deberá utilizar estrategias activas que permitan la participación del estudiante. (Departamento de Ediciones Educativas de Santillana, 2009)

\section{Materiales}

\section{El docente debe elegir los materiales:}

De acuerdo a los propósitos que se quieren alcanzar, el proceso didáctico y los contenidos que se van a desarrollar. Los materiales se dividen en: los que servirán de base para el nuevo aprendizaje: los que servirán para la evaluación final; y, en algunos casos, los que servirán para la transferencia. (Departamento de Ediciones Educativas de Santillana, 2009, p. 45)

El material que se usa para el aprendizaje tiene distintas características. La primera es que para que sea potencialmente significativo, debe poseer significado lógico: es decir, debe tener contenidos comprensibles para el estudiante y tiene que estar organizado de manera que el aprendiz pueda comprenderlo, porque es claro y sigue una lógica fácil para él. Esto significa que está escrito con oraciones claras y sencillas, que tiene explicaciones, ejemplos, etc. (Departamento de Ediciones Educativas de Santillana, 2009, p. 45) 
La segunda condición que debe cumplir el material es tener en cuenta las ideas que el aprendiz ya posee para que las pueda relacionar con las nuevas. Es decir, que el material sea diseñado de manera que tenga relación con lo que saben los estudiantes. Para ello el lenguaje y las palabras que se utilizan deben ser previamente conocidos por los alumnos. Esto permitirá que los nuevos contenidos presentados en el material puedan ser comprendidos, pues parten de prerrequisitos y permiten que los estudiantes los enlacen con el nuevo contenido. (Departamento de Ediciones Educativas de Santillana, 2009, p. 45)

\section{Tiempo}

El aprendizaje significativo lleva un tiempo para consolidarse en los estudiantes, no se lo logra rápidamente. Por lo tanto, el docente debe ser perseverante en aquel proceso; debe ayudar a que los estudiantes lo adquieran aplicando refuerzos pedagógicos con la ayuda de temas o situaciones prácticas similares a las del tema ya tratado. (Rodríguez, 2008)

\section{Lenguaje}

El ser humano se relaciona socialmente a través del lenguaje, de la misma manera dentro del aula de clase el lenguaje es imprescindible para llevar a cabo el proceso educacional. Sin un léxico adecuado y una interacción oral libre no se podrá compartir ideas entre el estudiante y el docente. (Rodríguez, 2008).

\section{Metodología.}

Esta investigación está enmarcada en el modelo pedagógico crítico-constructivo, el mismo que conduce a estudiar la incidencia que tiene la variable independiente (la música infantil) sobre la variable dependiente (aprendizaje significativo). Para esto se realizaron encuestas a una población conformada por 68 personas ( 2 docentes y 66 estudiantes de tercer año de E.G.B. de la Unidad Educativa "Hispano América"), con la debida autorización por parte de las autoridades de la institución. Cabe mencionar que se trabajó con la totalidad de la población, por ser menor a 100 .

Para aplicar los instrumentos de investigación, se acudió a la institución educativa en mención, específicamente a los paralelos "A" y "B" de tercer año de E.G.B., en los cuales se orientó a los estudiantes en el desarrollo de la encuesta y se explicó el objetivo de la misma, de igual manera a los docentes. Luego se analizaron e interpretaron los resultados obtenidos, mediante representaciones gráficas y descripciones con la ayuda del programa Excel.

Después de haber sintetizado los resultados, se procedió a realizar la verificación de la hipótesis mediante la aplicación del Chi-Cuadrado, que permitió aceptar la hipótesis afirmativa. Finalmente se establecieron conclusiones y recomendaciones en base a los datos recopilados. Por otra parte, la fundamentación científica-teórica de este trabajo, está sustentado con coherencia y solidez en fuentes bibliográficas suficientes (libros, revistas, fuentes de internet y otros estudios científicos afines al tema). 


\section{ISSN: 2602-8085}

Tabla 1. Población

\begin{tabular}{ccc}
\hline Investigados & Frecuencia & Porcentaje \\
\hline Estudiantes & 66 & $97 \%$ \\
Profesores & 2 & $3 \%$ \\
TOTAL & 68 & $100 \%$ \\
\hline
\end{tabular}

Estudiantes y docentes de tercer año paralelo "A" y "B" de la Unidad Educativa "Hispano América", cantón Ambato, a quienes se les aplicó las encuestas.

\section{Resultados.}

En base al proceso de recolección de información de la presente investigación, se presentan los resultados de las encuestas aplicadas a los docentes y estudiantes del tercer año de E.G.B. paralelos "A" y "B" de la Unidad Educativa "Hispano América" del cantón Ambato.

Fig. 1 El siguiente gráfico representa los resultados obtenidos de las encuestas aplicadas a docentes y estudiantes y se puede verificar que la música infantil incide en el desarrollo del aprendizaje significativo.

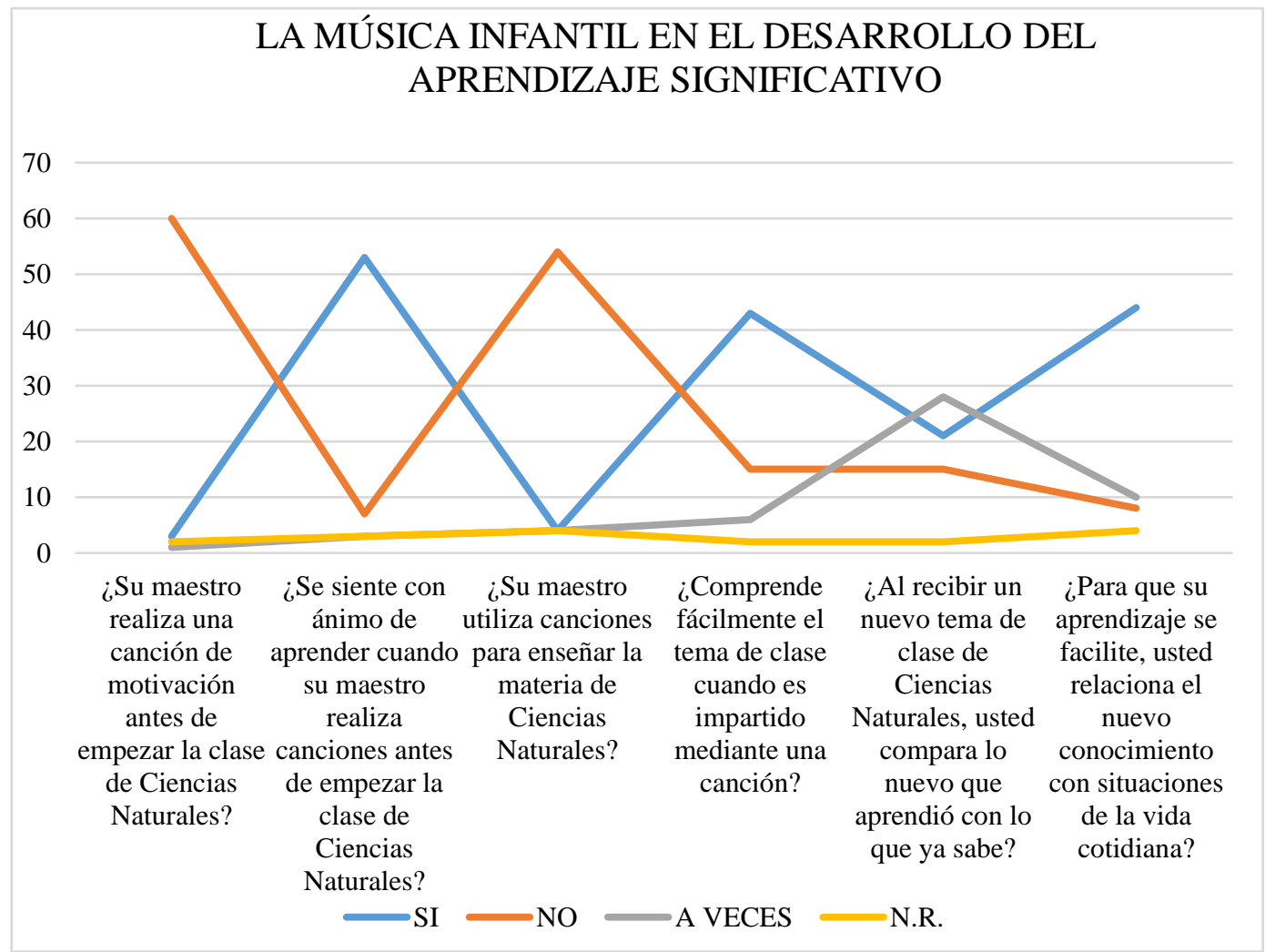


Al cuestionar sobre el aspecto motivacional de la música infantil; de un total de 66 estudiantes encuestados que corresponden al 100\%, el $91 \%$ responden que al iniciar la clase el maestro no realiza canciones de motivación, el $5 \%$ responde que sí, el 1\% responde que lo hace a veces y el $3 \%$ no contesta esta pregunta. Por lo tanto, la gran mayoría de los estudiantes asegura que su maestro no realiza una canción de motivación antes de iniciar la clase de Ciencias Naturales, lo que quiere decir que este recurso es muy poco utilizado con el fin de motivar a los alumnos. Por consiguiente, están obligados a recibir sus clases de una manera tradicional, sin participar activamente en el proceso educacional.

Dentro del mismo de la misma categoría (motivacional), $80 \%$ de los alumnos responden que se sienten con ánimo de aprender cuando su maestro realiza canciones de motivación antes de empezar la clase de Ciencias Naturales, el $11 \%$ responde que no, el $4 \%$ responde a veces y el $5 \%$ no contestan esta pregunta. Lo que significa que las tres cuartas partes de los estudiantes logran motivarse para su aprendizaje cuando el docente realiza una canción previa al iniciar la clase. Esto lo logran ya que al combinar una melodía, armonía, la letra y el movimiento corporal su estructura cognitiva se activa. Por lo tanto, en la clase habrá la interacción entre docente y alumnos y también entre pares, así se facilitará el proceso de enseñanza-aprendizaje.

En cuanto al uso de canciones que ayuden a adquirir un aprendizaje significativo; de un total de 66 estudiantes encuestados que corresponden al 100\%, el $82 \%$ responden que su maestro no utiliza canciones para enseñar los temas de Ciencias Naturales, el $6 \%$ responde que sí, el $6 \%$ responde que lo hace a veces y el otro $6 \%$ que no contesta esta pregunta. Por lo tanto, la mayoría de los estudiantes manifiestan que su maestro no enseña la materia de Ciencias Naturales mediante el uso de canciones, ya que generalmente lo hacen con el método común de enseñanza que todo docente aplica: el expositivo. En consecuencia, el proceso educacional dentro del aula de clase se torna monótono y poco llamativo para los educandos. Además, no está adaptado a los estilos de aprendizaje de todos los estudiantes.

Dentro del ámbito de comprensión mediante el uso de canciones; de un total de 66 estudiantes encuestados que corresponden al 100\%, el 66\% responden que comprenden fácilmente el tema de clase cuando es impartido mediante una canción, el $23 \%$ responde que no, el $9 \%$ responde a veces y el $2 \%$ no contesta esta pregunta. Lo que quiere decir que más de la mitad de los estudiantes comprenden fácilmente un tema de clase de Ciencias Naturales cuando su maestro les enseña con la aplicación de canciones porque es un recurso pedagógico lúdico y muy versátil adaptado a todos los estilos de aprendizaje de los estudiantes como: visual, auditivo y quinestésico.

Relación de conocimientos previos con nuevos; de un total de 66 estudiantes encuestados que corresponden al $100 \%$, el $32 \%$ responden que, al recibir un nuevo tema de clase de Ciencias Naturales, ellos comparan lo nuevo que aprendieron con lo que ya saben, el $23 \%$ responde que no, el $43 \%$ responde a veces y el $2 \%$ no contesta esta pregunta. Esto significa 
que menos de la mitad del alumnado hace comparaciones de lo que ya conoce sobre un tema con la información nueva que recibe. Esto se debe a que sus conocimientos previos no están bien cimentados y en cada sesión pedagógica debe empezar a analizar y asimilar la información desde cero, lo cual dificulta hacerlo de manera sencilla y necesitará de refuerzo constante.

Adquisición de conocimientos en base a comparaciones con aspectos de la vida cotidiana; de un total de 66 estudiantes encuestados que corresponden al 100\%, el 69\% responden que, para que su aprendizaje se facilite, ellos relacionan el nuevo contenido con situaciones de la vida cotidiana, el $13 \%$ responde que no, el $16 \%$ responde a veces y el $2 \%$ no contesta esta pregunta. Esto significa que las tres cuartas partes de los alumnos hacen relaciones del nuevo contenido con situaciones de la vida cotidiana para facilitar su aprendizaje. Al realizar este proceso de comparación, ellos comprenderán, memorizarán y recordaran con mayor facilidad ciertos conceptos y teorías científicas que en el área de Ciencias Naturales son un tanto complejas.

\section{Conclusiones.}

- La música infantil es aplicada por los docentes como un medio de motivación intrínseca para cumplir con el proceso de enseñanza-aprendizaje, pero se lo hace muy pocas veces y solo en años de educación básica inferiores. Sin embargo, su uso no trasciende al logro de objetivos más concretos como el de desarrollar el aprendizaje significativo de los estudiantes dentro de la práctica pedagógica diaria, es decir de facilitar la comprensión y retención de los contenidos académicos como prerrequisitos para aprender otros con más profundidad.

- Según el análisis de los resultados obtenidos de las encuestas realizadas a docentes y alumnos de Tercer Año de E.G.B. de la Unidad Educativa "Hispano América" del Cantón Ambato, se demuestra que las pocas veces que el docente aplica la música infantil como herramienta para impartir su clase, los estudiantes comprenden muy bien el contenido académico en el área de Ciencias Naturales. Por otro lado, al aprender un nuevo tema, los estudiantes no tienen aún una breve idea de lo que se trata, puesto que no han adquirido un aprendizaje significativo antes como prerrequisito para captar otro más complejo. Además, la comparación de conceptos científicos y teorías nuevas con situaciones de la vida cotidiana facilita en gran medida la adquisición y la comprensión del conocimiento. Sin embargo, los maestros no ayudan a que sus estudiantes lo hagan siempre.

- A partir de la verificación de la hipótesis, se concluye que la música infantil sí influye en gran medida en el desarrollo del aprendizaje significativo de los estudiantes de Tercer Año de E.G.B. en la Unidad Educativa "Hispano América", porque al utilizarla como recurso dentro del proceso de enseñanza-aprendizaje permite que los alumnos desarrollen habilidades ocultas dentro de ellos, puesto que el arte es también un muy buen medio, no solo la ciencia. A través de la música los estudiantes desarrollan la creatividad, la 
concentración, la comprensión y la retención de información, la lógica y la crítica. Además, se mejoran las habilidades inter e intrapersonales, cumpliendo así con las competencias requeridas en un ciudadano integral que son: el saber ser (actitudes), el saber hacer (habilidades y destrezas) y el saber saber (conocimientos).

\section{Referencias bibliográficas.}

Bernabeu, N., \& Goldstein, A. (2009). CREATIVIDAD Y APRENDIZAJE: El juego como herramienta pedagógica. Madrid: Narcea.

Currículo del área de Educación Cultural y Artística (E.C.A.). (2016). Introducción general del currículo de la E.G.B. y del B.G.U. .

García, M. (2010). LA MÚSICA COMO RECURSO DIDÁCTICO. Eduinnova, 155-156.

Lago, P. (2012). En L. m. diversidad. Madrid.

Moreno, I. (2004). Obtenido de http://webs.ucm.es/info/doe/profe/isidro/merecur.pdf

Rodríguez, L. (Noviembre de 2008). Obtenido de https://elibros.octaedro.com/appl/botiga/client/img/10112.pdf

Tünnermann, C. (2011). El constructivismo y el aprendizaje de los estudiantes. Red de Revistas Científicas de América Latina (REDALYC), 25. 


\section{PARA CITAR EL ARTÍCULO INDEXADO.}

Cunalata Ramón, S., \& Aldás Rovayo, V. (2019). La música infantil para desarrollar el aprendizaje significativo en el área Ciencias Naturales. Ciencia Digital, 3(2.6), 87103. https://doi.org/10.33262/cienciadigital.v3i2.6.520

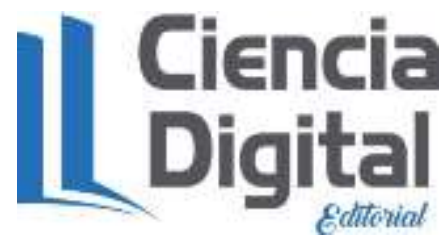

El artículo que se publica es de exclusiva responsabilidad de los autores y no necesariamente reflejan el pensamiento de la Revista Ciencia Digital.

El artículo queda en propiedad de la revista y, por tanto, su publicación parcial y/o total en otro medio tiene que ser autorizado por el director de la

\section{Revista Ciencia Digital.}
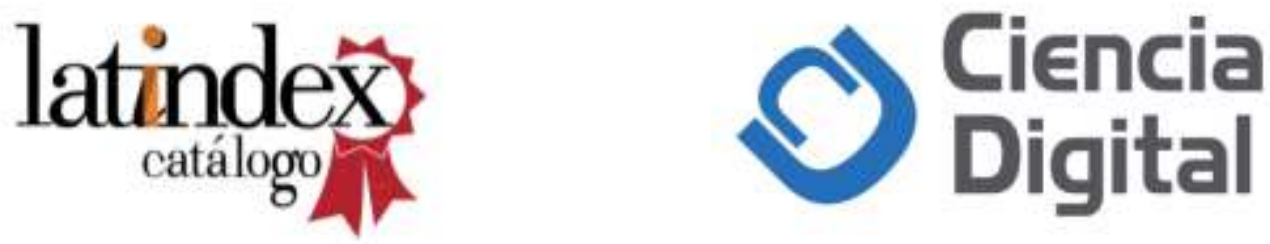